\title{
Case Study in Systematic Design Engineering - Wind TunNel Balance Model Support
}

\author{
W. Ernst Eder \\ Professor Emeritus, Dr.h.c., Royal Military College of Canada (retired) \\ eder-e@ko.net
}

\begin{abstract}
Students learning design engineering at times need a good example of procedure for novel design engineering. The systematic heuristic-strategic use of a theory to guide the design process - Engineering Design Science - and the methodical design process followed in this case study is only necessary in limited situations. The full procedure should be learned, such that the student can select appropriate parts for other applications.

Creativity is usually characterized by a wide search for solutions, especially those that are innovative. The search can be helped by this systematic and methodical approach.

This case example is presented to show application of the recommended method, and the expected scope of the output, with emphasis on the stages of conceptualizing. The case follows a novel design problem of an auxiliary attachment to render a wind tunnel balance more versatile to accommodate several different test models.
\end{abstract}

Keywords: Systematic design engineering, theory-based method, worked case example.

\section{INTRODUCTION}

Students learning design engineering at times need a good example of procedure for novel design engineering. The systematic and methodical design process followed in this case study is abridged from [1][2]. As shown in a paper presented at a previous conference [3], such a fully systematic procedure is only necessary in limited situations, when an engineering designer is faced with an unfamiliar and non-routine situation. Systematic design engineering as a procedure is the heuristic-strategic use of a theory to guide the design process - Engineering Design Science [1][2][4] is recommended as guiding theory. Methodical design engineering as a procedure is the heuristic use of newly developed and established methods within the engineering design process, including theory-based and 'industry best practice', strategic and tactical, formalized and intuitive methods. Systematic and methodical procedures have a substantial overlap, but are not co-incident. The full procedure should be learned, such that the student can select appropriate parts for other applications.

Creativity [5] is usually characterized by a wide search for solutions, especially those that are innovative. This search can be supported by the recommended systematic and methodical approach. All generated alternatives should be kept on record, to allow re-tracing and recovery from subsequent detection of a better alternative. Each step in the overall procedure should be concluded by selecting the most appropriate (one or two) solutions for further processing, in order to control a tendency towards 'combinatorial complexity'.

The first case study, systematic according to the state of the theory and method at that time, appeared in 1976 [6] - a machine vice. The second appeared in 1980 [7] - a welding positioner. The next three, also systematic, were published in 1981 in German - a riveting fixture, a milling jig, and a powder-coating machine. The third set was published in 1983 - a P-V-T-experiment, a hand winding machine for tapes, and a tea brewing machine the first two were systematic, the third took an industrialartistic design approach. An English edition was published in 1988 [8], and included the existing six case studies, plus two new items - a wave-powered bilge pump, and an oil drain valve - and again the bilge pump only loosely followed the systematic method. Three further case studies were published in 2008 [2] - the tea machine revised to current systematic procedures showing enhanced engineering information; re-design of a water valve; and an electro-static smoke gas dust precipitator, with rapper for dust removal [9]. The currently last three case examples were published in 2010 [2] - a trapeze demonstration rig [12], re-design of an automotive oil pump [13], and a hospital emergency bed, with compensation devices for the support arrangement. Two other cases have now been prepared for the International Conference DESIGN 2012 [14][15], both from the Caravan Stage Barge [16] which has been in operation in Canadian and U.S.A. coastal waters, and now in the Mediterranean, since 1995. 
The primary purpose of these case studies is to present examples for procedural application of the recommended engineering design method that students and practitioners can follow and study to help learn the scope of the method and its models. This purpose has been applied in courses at the Eidgenössische Technische Hochschule (ETH) by Dr. Vladimir Hubka (1976-2000), at The Royal Military College of Canada (1981-2006), and at the University of West Bohemia (1990-present) - for all levels of education and for industry consultations. A secondary purpose was to verify and validate the theory and its models, and the method derived from the theory. The emphasis in all case studies was on the engineering design procedure and use of the models, the chosen technical systems in several case studies were not necessarily optimal.

The systematic procedure must be adapted to the problem. The cases demonstrate that an engineering designer can idiosyncratically interpret the models to suit the problem, and develop information in consultation with a sponsor. Opinions will vary about whether a requirement should be stated in the class of properties as shown, or would be appropriate in a different class.

This case example is presented to show application of the recommended method, and the expected scope of the output, with emphasis on the stages of conceptualizing. The embodying/laying out and detailing stage is regarded as more routine.

The international standard ISO 9000:2005 defines two sorts of technological, artificial, human-made systems:

- process systems, consisting of operations transformation process (TrfP) transforming an operand;

- tangible object systems, consisting of (tangible) constructional parts, with organs and functions technical systems (TS), if they have substantial engineering content.

Figure 1 shows the basic model on which the theory and method are based. This model of the transformation system declares:

An operand (materials, energy, information, and/or living things - M, E, I, L) in state Od1 is transformed into state Od2, using the active and reactive effects (in the form of materials, energy and/or information - $M$, E, I) exerted continuously, intermittently or instantaneously by the operators (human systems, technical systems, active and reactive environment, information systems, and management systems, as outputs from their internal processes), by applying a suitable technology $\mathrm{Tg}$ (which mediates the exchange of $\mathrm{M}, \mathrm{E}$, I between effects and operand), whereby assisting inputs are needed, and secondary inputs and outputs can occur for the operand and for the operators.

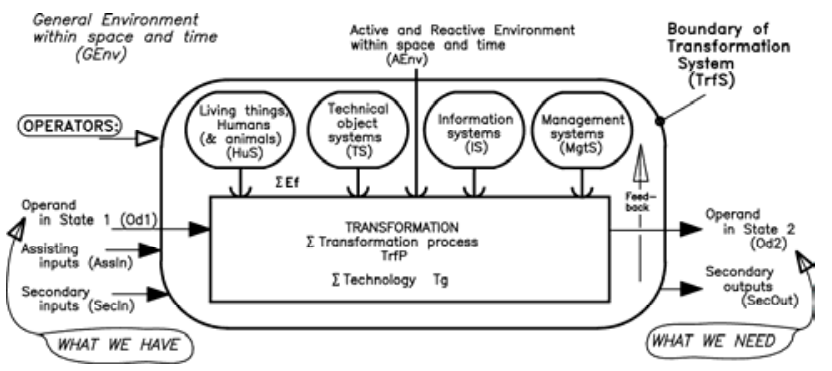

Figure 1 General Model of a Transformation System [1][2]

Using this model as basis, the stages and steps of a novel design process [1][2] are summarized as:

- task defining:

(P1) establish a design specification for the required system, a list of requirements;

(P2) establish a plan and timeline for design engineering; - conceptualizing

(P3a) from the desirable and required output (operand in state Od2), establish a suitable transformation process $\operatorname{TrfP}(\mathrm{s})$,

(P3.1.1) if needed, establish the appropriate input (operand in state Od1);

(P3.1.2) decide which of the operations in the TrfP(s) will be performed by technical systems, TS, alone or in mutual cooperation with other operators; and which TS(s) (or parts of them) need to be designed;

(P3.1.3) establish a technology (structure, with alternatives) for that transformation operation, and therefore the effects (as outputs) needed from the technical system;

(P3b) establish what the technical system needs to be able to do (its internal and cross-boundary functions, with alternatives);

(P4) establish what organs (function-carriers in principle and their structure, with alternatives) can perform these functions. These organs can be found mainly in prior art, especially the machine elements, in a revised arrangement as proposed by Weber [17][18][19];

- embodying/laying out and detailing:

(P5a) establish what constructional parts and their arrangement are needed, in sketch-outline, in rough layout, with alternatives;

(P5b) establish what constructional parts are needed, in dimensional-definitive layout, with alternatives;

(P6) establish what constructional parts are needed, in detail and assembly drawings, with alternatives.

The suffix '(s)' indicates that this $\operatorname{TrfP}(\mathrm{s})$ and/or TS(s) is the subject of interest. Only those parts of this engineering design process that are thought to be useful are employed. Such an 'idealized' procedure cannot be accomplished in a linear fashion - iterative and recursive working is essential, using analysis and synthesis [20]. 
PROCEDURAL NOTE: Compare the output of each stage with the theoretical figures from [1][2] to check whether any important elements may be missing. Procedural notes such as this may be interspersed with the case to explain some aspects of the procedure.

\section{CASE STUDY - WIND TUNNEL BALANCE MODEL SUPPORT}

A wind tunnel was designed and built in the Mechanical Engineering Department of The Royal Military College of Canada, Kingston, Ontario, in the early 1970 's. Its working section is $42^{\prime \prime}$ wide, 30 " high, and 86" long. Its 3-component (lift, drag, pitching moment) force balance is movable along the air-flow axis to allow positioning any attached models, placed suitably relative to the working section entrance. A suitable support and positioning rail (a balance adapter) to attach some models to the balance was to be designed and made to render the balance more versatile.

Steps from the procedural model [1][2 (figure 11.1, $\mathrm{p}$. 219-222)] were considered, and the following review cycle was applied for each step:

\{Improve, optimize $\}-<$ Substantiate, evaluate, select, decide $>-\{$ Verify, check, reflect $\}$

- task defining:

(P1) establish a design specification for the required system, a list of requirements;

Requirements are listed only under the most relevant class of TrfP and/or TS-requirements as judged by the engineering designer, and cross-referenced if they are repeated in any other relevant requirement class [2 (figure 11.4 , p. 226-227)]. Indication of priority - F ... fixed requirement, must be fulfilled; S ... strong wish; W ... wish; $\mathrm{N}$... not considered.

Rq1 OrgRq Organization requirements (Rq1A-Rq1E)

F The project must be accomplished within the available funding.

F Coordination needed between designer (W.E. Eder) and initial users.

Rq2 TrfRq Requirements of the Transformation (Rq2A $-\mathrm{Rq} 2 \mathrm{E}$ )

F Existing balance must be removably mounted, and easily dis-mounted, with or without the model support.

F Model on balance adapter to be attachable and movable across the width of the working section, to within $6^{\prime \prime}$ of the side wall, stepwise or continuously variable. Balance adapter to be attached adjustably to attachment plate on wind tunnel balance, which is 8 " wide, 3/4" thick, $28.5^{\text {" long }}$ (across the working section), two rows of $3 / 8$ "UNC tapped holes at 7" centres, with 8 pitches of 1", 3 pitches of 1.5", and 8 pitches of 1 " centred along length.

F Working section must be easily removable from wind tunnel - this may influence the balance.

Rq3 EfRq Effects requirements of the TS (Rq3A $\mathrm{Rq} 3 \mathrm{C})$

F Model support to have minimal effect on operation of the wind tunnel balance

Rq4 MfgRq Manufacturing requirements

F All manufacture to be in Mech. Eng. Dept. Workshops

Rq5 DiRq Distribution requirements None

Rq6 LiqRq Liquidation requirements No toxic materials

Rq7 HuFRq Human factors requirements (Rq7A - Rq7G)

F Skilled technicians and research personnel

Rq8 TSFRq Requirements of factors of other TS (in their TrfP) (Rq8A - Rq8G)

Rq9 EnvFRq Environment factors requirements, LC1 LC7 (Rq9A - Rq9B)

Rq10 ISFRq Information system factors requirements, LC1 - LC7 (Rq10A - Rq10F)

Rq11 MgtFRq Management factors requirements

Rq11A Management planning, LC1

Rq11B Management of design and manufacturing process, LC2 - LC4,

$\mathrm{F} \quad$ By main engineering designer (W.E. Eder) in cooperation with Technical Officer $(\mathrm{O}$. Koroluk)

Rq11C Design documentation, LC2,

F Kept by Mech. Eng. Department (wind tunnel supervision)

Rq11D Situation, LC2

Rq11E Quality system.

Rq11F Information requirements

Rq11G Economic requirements

$\mathrm{Rq11H}$ Time requirements

F Must be completely manufactured and tested before end August 1995

Rq11J Tangible resources

F Materials acquired from standard suppliers

Rq11K Organization

Rq11L Supply chain requirements

Rq11M Other management aspects

DesRq Engineering design requirements for $\operatorname{TrfP}(\mathrm{s})$ and TS(s) (Rq12 - Rq14)

None. 
(P2) establish a plan and timeline for design engineering;

Aim for completed design documentation end of June 1995.

- conceptualizing:

(P3a) from the desirable and required output (operand in state Od2), establish a suitable transformation process $\operatorname{TrfP}(\mathrm{s})$,

(P3.1.1) if needed, establish the appropriate input (operand in state Od1);

(P3.1.2) decide which of the operations in the $\operatorname{TrfP}(\mathrm{s})$ will be performed by technical systems, TS, alone or in mutual cooperation with other operators; and which TS(s) (or parts of them) need to be designed;

Transformation process see figure 2.

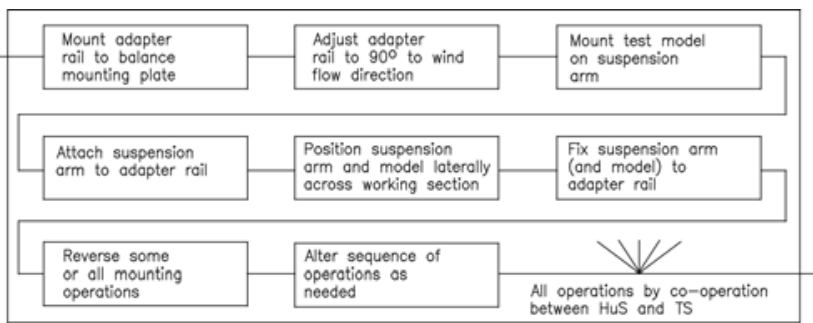

Figure 2 Transformation Process (TrfP) for Wind Tunnel Balance Adapter

(P3.1.3) establish a technology (structure, with alternatives) for that transformation operation, and therefore the effects (as outputs) needed from the technical system;

Available technology alternatives see figure 3 .

A) Support arm attachment to adapter rail:

A1) slide from end of rail

A2) clip onto rail from any position along rail

B) Positioning along adapter rail:

B1) stepwise, establish positions at regular intervals

B2) continuous, fix position by friction against rail

Figure 3 Technologies for Wind Tunnel Balance Adapter

Preferred technologies are A2) and B2).

(P3b) establish what the technical system needs to be able to do (its internal and cross-boundary functions, with alternatives);

The TS-function structure developed for this project is shown in figure 4. Most of these TS-functions are solvable by routine means. Only the numbered functions are variable, and therefore entered into a morphological matrix.

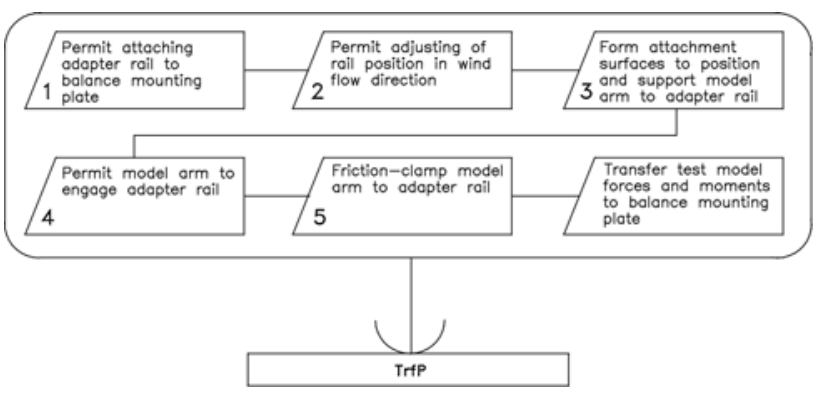

Figure 4 TS-Function Structure for Wind Tunnel Balance Adapter

(P4) establish what organs (function-carriers in principle and their structure, with alternatives) can perform these functions;

Figure 5 shows a morphological matrix, and figure 6 shows the selected TS-organ structure.

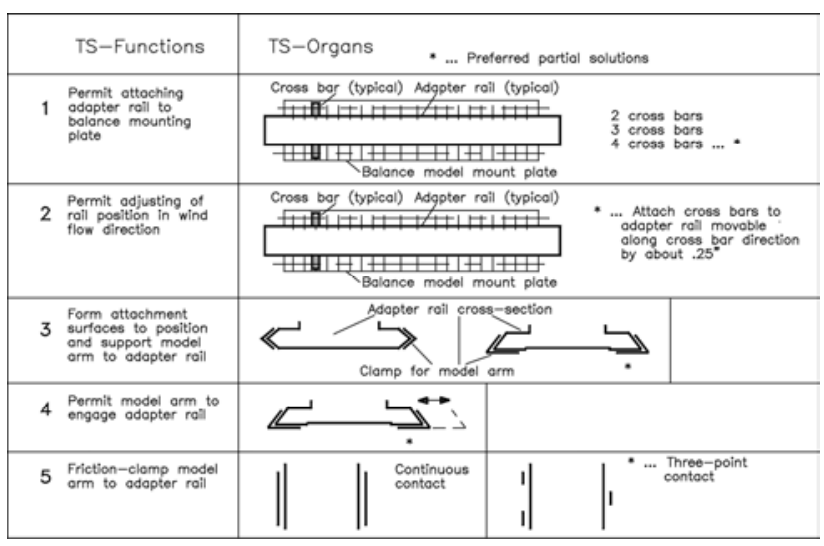

Figure 5 Morphological Matrix for Wind Tunnel Balance Adapter

The most promising with least difficulties appears to be a dovetail slide geometry, it provides a flat reference surface for any needed measurements downward to the test model.

- embodying/laying out and detailing:

(P5a) establish what constructional parts and their arrangement are needed, in sketch-outline, in rough layout, with alternatives;

The organ structure developed for this project is shown in figure 6 . 


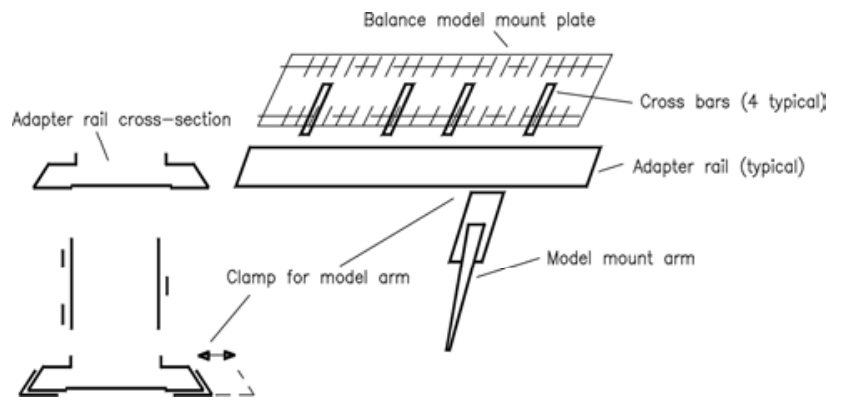

Figure 6 TS-Organ Structure for Wind Tunnel Balance Adapter

(P5b) establish what constructional parts are needed, in dimensional-definitive layout, with alternatives;

(P6) establish what constructional parts are needed, in detail and assembly drawings, with alternatives.

A dimensional layout, and a sample detail drawing are shown in figure 7 .

\section{CLOSURE}

The prescribed length of paper does not allow a fuller discussion of the recommended method, but see [1][2]. A more experienced engineering designer will no doubt be able to reach a similar result whilst neglecting one or more of the earlier of these formal steps and models.

\section{References}

[1] Eder, W.E. and Hosnedl, S (2008) Design Engineering: A Manual for Enhanced Creativity, Boca Raton: CRCPress

[2] Eder, W.E. and Hosnedl, S. (2010) Introduction to Design Engineering - Systematic Creativity and Management, Leiden (The Netherlands): CRC Press / Balkema (in press)

[3] Eder, W.E. (2009) 'Why Systematic Design Engineering?' in Proc. $6^{\text {th }}$ Symposium on International Design and Design Education, August 30 - September 2, 2009, San Diego, California, USA, New York: ASME, paper number DETC2009-86067

[4] Hubka, V. \& Eder, W.E. (1996) Design Science: Introduction to the Needs, Scope and Organization of Engineering Design Knowledge, London: SpringerVerlag, http://deseng.ryerson.ca/DesignScience/

[5] Eder, W.E. (ed.) (1996) WDK 24 - EDC - Engineering Design and Creativity - Proceedings of the Workshop EDC, Pilsen, Czech Republic, November 1995, Zürich: Heurista
[6] Eder, W.E., 'Requirements to Properties - Iterative Problem Solving', in Proc. Canadian Engineering Education Association 2010 Inaugural Conference, 7-9 June 2010, Queen's University, Kingston, ON

[7] Hubka, V. (1976) Theorie der Konstruktionsprozesse (Theory of Design Processes), Berlin: Springer-Verlag

[8] Hubka, V. and W.E. Eder (1992) Engineering Design, Zürich: Heurista, $\left(2^{\text {nd }}\right.$ edition of Hubka, V., Principles of Engineering Design, London: Butterworth Scientific, 1982, translated and edited by W.E. Eder from Hubka, V., WDK 1 - Allgemeines Vorgehensmodell des Konstruierens (General Procedural Model of Designing), Zürich, Heurista, 1980; translated into several other languages: French, M. Wyss (1980) Zürich: Heurista; Italian, U. Pighini (1982) Marsilo ed.; Czech, S. Hosnedl (1995) Zürich: Heurista, and others)

[9] Hubka, V., Andreasen, M.M. and Eder, W.E. (1988) Practical Studies in Systematic Design, London: Butterworths, (English edition of WDK 4 - Fallbeispiele, Zürich: Heurista, 1981 and 1983)

[10] Eder, W.E., 'Case Study in Design Engineering' in Proc. CDEN 06 Toronto, 24-26 July 2006, on CD-ROM p. $332-338$

[11] Eder, W.E., 'Case Study in Systematic Design Engineering - Smoke Gas Dust Precipitation', paper ASME DETC2009-86069 in Proceedings of the $6^{\text {th }}$ Symposium on International Design and Design Education, DEC 6, August 30 - September 2, 2009, San Diego, California, USA

[12] Eder, W.E., 'Case Study in Systematic Design Engineering - Trapeze Demonstration Rig', paper ASME DETC2010-28065 in Proc. $7^{\text {th }}$ Symposium on International Design and Design Education, DEC 7, 15-18 August 2010, Montreal, Quebec, Canada

[13] Eder, W.E. and Heffernan, P.J., 'A Case Study in Systematic and Methodical Design Engineering', in Proc. CDEN/C2C2 Conference 2009, 27-29 July 2009, McMaster University, Hamilton, ON

[14] Eder, W.E. (2012a) 'Case Example in Systematic Design Engineering - Leeboard Mounting', for Proc. International Design Conference - DESIGN 2012, Dubrovnik - Croatia, May 21-24, 2012

[15] Eder, W.E. (2012b) 'Case Example in Systematic Design Engineering - Propeller Shaft Bearing Arrangement', for Proc. International Design Conference - DESIGN 2012, Dubrovnik - Croatia, May 21-24, 2012

[16] http://www.caravanstage.org

[17] Weber, C. and Vajna, S. (1997) 'A New Approach to Design Elements (Machine Elements)'. In Riitahuhta, A. 
(ed.) WDK 25 - Proc. ICED 97 Tampere, Tampere University, Vol. 3, 1997, p. 685-690

[18] Eder, W.E. (2004) 'Machine Elements - Integration Of Some Proposals', Proc. AEDS 2004 Workshop, The Design Society - AEDS-SIG, 11-12 Nov 2004, Pilsen, Czech Republic, on CD-ROM, http://www.kks.zcu.cz/aeds
[19] Eder, W.E. (2005) 'Machine Elements - Revision and Outlook for Design Education', in Proc. Second CDEN International Conference, University of Calgary, Alberta, 18-19 July 2005 at Kananaskis Resort, paper 10006 on CD-ROM

[20] Eder, W.E. (2008) 'Aspects of Analysis and Synthesis in Design Engineering', in Proc. CDEN 08, Halifax, N.S., 27-29 July 2008, on CD-ROM
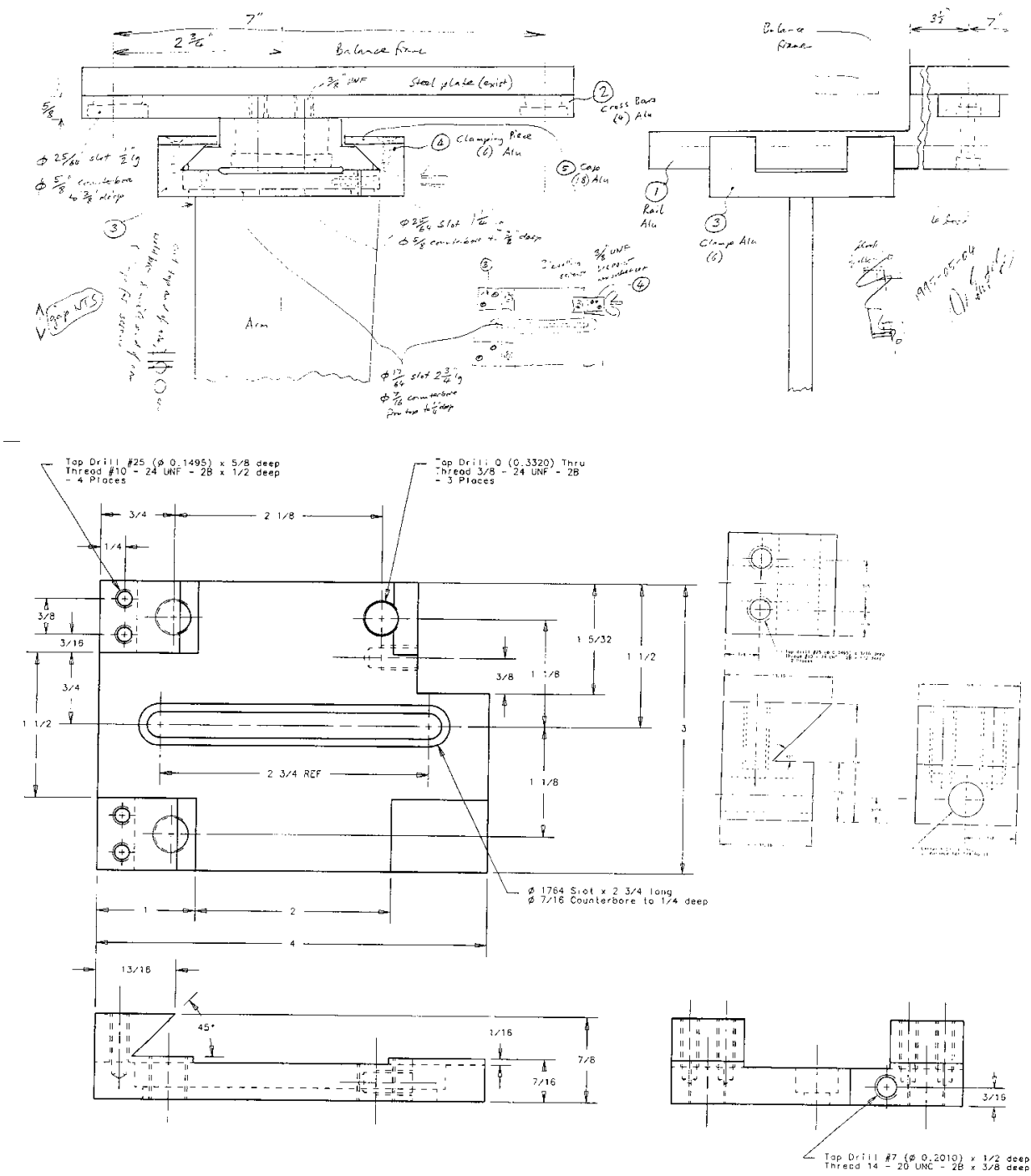

NOTE: Break all corners

Material: Alumimun Quantity: 6

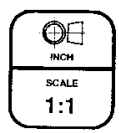

Figure 7 Layout and Detail Drawing Sample for Wind Tunnel Balance Adapter 